\title{
Restoration of sinus rhythm during two consecutive pregnancies in a woman with congenital complete heart block
}

\author{
Diana R Holdright, G C Sutton
}

\begin{abstract}
In a woman with congenital complete heart block atrioventricular conduction was normal during two successive pregnancies. Pregnancy, labour, and delivery were uncomplicated on both occasions and complete heart block returned post partum.
\end{abstract}

Successful pregnancies have been reported in many patients with congenital complete heart block. ${ }^{1-3}$ The restoration of normal atrioventricular conduction during pregnancy in a patient with congenital complete heart block is unusual, however. We report a patient in whom atrioventricular conduction became normal during two successive pregnancies, while complete heart block was the predominant rhythm when the patient was not pregnant.

\section{Case report}

A Cypriot woman had been found coincidentally to have complete heart block at the age of 10 years, but was not informed of this until some years later. She was assessed for the first time at the age of 21 . At that time she was aware of heart rate changes, particularly when the rate increased, and she was occasionally dizzy when her rate fell below 40 beats/minute; she had never had any syncopal episodes. She had no significant illness in her life and there was no relevant family history. She was not receiving any medication.

Apart from bradycardia of 50 beats/minute examination was unremarkable. Review of her electrocardiograms showed that at the age of 10 years she had complete atrioventricular block with normal QRST-T complexes and a ventricular rate of 42 beats/minute. Subsequent electrocardiograms showed sinus rhythm with a normal PR interval (aged 17 years), first degree heart block (PR interval of $0.22 \mathrm{~s}$ ) (aged 21 years), and advanced second degree atrioventricular block (aged 23 years). Holter monitoring when she was 21 showed episodes of sinus tachycardia (130 beats/ minute) and nocturnal complete heart block. Her chest $x$ ray and an echocardiogram were normal.

In 1986, when she became pregnant for the first time she had normal atrioventricular conduction with a long PR interval (0.2-0.24 s). Holter monitoring at 32 weeks of pregnancy showed occasional periods of complete heart block with no specific diurnal pattern. Labour was spontaneous and during the second stage sinus tachycardia developed with a ventricular rate of 120 beats/minute. She had an uncomplicated delivery and post partum complete heart block returned. In 1988 she became pregnant for the second time, and again atrioventricular conduction became normal with a PR interval of $0.2 \mathrm{~s}$. Her pregnancy was unremarkable and she had a sinus tachycardia during delivery. Almost immediately after delivery she returned to complete heart block alternating with advanced second degree atrioventricular block.

A month after the second pregnancy an exercise test was performed and she managed 9 minutes of the Bruce protocol, stopping because of breathlessness. Her resting ventricular rate was 60 beats/minute with a PR interval of $0.24 \mathrm{~s}$. Her resting blood pressure was $110 / 65 \mathrm{~mm} \mathrm{Hg}$. At peak exercise the ventricular rate was 140 beats/minute, the PR interval was unchanged, and the systolic blood pressure was $130 \mathrm{~mm} \mathrm{Hg}$. Two minutes into recovery a 2:1 second degree atrioventricular block developed with a ventricular rate of 60 beats/minute.

\section{Discussion}

Congenital complete heart block was first described by Morquio in $1901 .^{4}$ The diagnosis is made if the criteria established by Yater $^{5}$ are fulfilled-heart block must be demonstrated electrocardiographically and a slow pulse ascertained at an early age; there must be no history of infection such as diphtheria or rheumatic fever and no evidence of ischaemic heart disease or other cardiomyopathy, nor a history of previous cardiac surgery. The incidence is approximately 1 in 15000 to 22000 live births ${ }^{67}$ and, unlike acquired complete heart block, the QRS complex is usually narrow.

The ventricular response to exercise is generally more pronounced than in acquired complete heart block. In our patient, albeit one month post partum, sinus tachycardia with a constant PR interval developed during an exercise test but two minutes after maximum tolerated work load a 2:1 second degree atrioventricular block supervened.

Complete heart block has been shown to disappear in some patients, with sinus rhythm being restored sometimes for several years. This is more common in congenital than acquired complete heart block. Indeed some patients change constantly between first, second, and third degree heart block-that is incomplete complete heart block. Even before pregnancy our patient had documented 
episodes of sinus rhythm in 1975,1977 , and 1981.

Many successful pregnancies have been reported in patients with congenital heart block but Adams-Stokes attacks may develop during delivery. This may be precipitated in part by the Valsalva manoeuvre which slows the ventricular rate. Esscher described pregnancies in 12 women with congenital heart block. ${ }^{1}$ Ten patients had 19 pregnancies with no complications while in two patients Adams-Stokes attacks developed during three pregnancies. The development and maintenance of sinus tachycardia during delivery reduced the likelihood of a syncopal episode in our patient.

We speculate that the hormonal changes of pregnancy - with increased production of oestrogens, progesterone, and corticosteroids may have improved atrioventricular conduction in our patient. It has long been recognised that steroids can improve atrioventricular conduction. In 1955 Lown et al showed that the PR interval was longer in Addison's disease and shorter in Cushing's syndrome than in healthy individuals. ${ }^{10}$ Hormone replacement treatment improved atrioventricular conduction in those patients with Addison's disease. Patients with Cushing's syndrome had either a short PR interval or a normal PR interval. In general, those patients with a short PR interval had adrenal cortical hyperplasia and urinary excretion of 17-ketosteroids (an indicator of adrenal cortical function) that was four times higher than that in the group with a normal PR interval who at surgery were found to have adrenal adenomas.

There is a well recognised association between maternal systemic lupus erythematosus and complete heart block developing in utero. The conduction tissue damage in utero does not continue in adult life, however. Thus it seems improbable that the hormonal changes of pregnancy could have mitigated the effects of lupus in our patient, who in any case had no overt clinical features suggestive of lupus erythematosus (specific serological testing was not performed). Alternatively, rather than producing structural changes in the conducting tissues, steroids might produce their effect by altering the intracellular-extracellular balance of electrolytes, in particular producing a net shift of potassium out of cells. Improved atrioventricular conduction in patients with complete heart block treated with chlorothiazide $^{11}$ was associated with a fall in extracellular potassium.

It is not known whether or not oestrogens or progesterone could have an effect on atrioventricular conduction; there are no published studies.

It is likely that the hormonal changes of pregnancy encouraged the restoration of sinus rhythm in our patient. This improvement in atrioventricular conduction might indicate a better prognosis than in those patients in whom complete atrioventricular block persists during pregnancy.

We thank Dr E Rowland for his advice and Mr C Wright who delivered the patient of her two children.

1 Esscher EB. Congenital complete heart block in adolescence and adult life. A follow-up study. Eur Heart J 1981;2: 281-8.

2 Eddy WA, Frankenfeld RH. Congenital complete heart block in pregnancy. Am J Obstet Gynecol 1977;128:223-6.

3 Abramovici H, Faktor JH, Gonen Y, Brandes M, Amikam S. Maternal permanent bradycardia: pregnancy and delivery. Obstet Gynecol 1984;6:381-3.

4 Morquio L. Sur une maladie infantile et familiale caracterise par des modifications permanentes du pouls, des attaques syncopales et epileptiformes et la mort subite. Arch Med Enfants 1901;4:467-75.

5 Yater WM. Congenital heart block. Review of the literature, report of a case with incomplete heterotaxy; the electrocar-

6 Landtman B, Linder E, Hjelt L, Tuuteri L. Congenital complete heart block. A clinical study of 37 cases. Ann Paediatr Fenn. 1964;10:99-104.

7 Gochberg SH. Congenital heart block. Am J Obstet Gynecol 1964;88:238.

8 Rytand DA, Stinson E, Kelly JJ. Remission and recovery from chronic, established, complete heart block. $A m$ Heart J 1976;91:645-52.

9 Dewhurst Sir J, ed. Integrated obstetrics $\mathcal{E}$ gynaecology for postgraduates. 3rd ed. Ox.

10 Lown B, Arons WL, Ganong WF, Vazifdar JP, Levine SA. Adrenal steroids and auriculoventricular conduction. Am Adrenal steroids and auric

11 Tobian L. Prevention of Stokes-Adams seizures with chlorothiazide. N Engl J Med 1961;265:623-8. 